\title{
Variation in Lipoprotein(a) Concentration Associated with Different Apolipoprotein(a) Alleles
}

Y. F. Nicholas Perombelon, Anne K. Soutar, and Brian L. Knight

MRC Lipoprotein Team, Hammersmith Hospital, London W12 OHS, United Kingdom

\begin{abstract}
Plasma lipoprotein(a) (Lp(a)) concentrations vary considerably between individuals. To examine the variation for products of the same and different apolipoprotein(a) (apo(a)) alleles, conditions were established whereby phenotyping immunoblots could be used to estimate the concentration of $\mathrm{Lp}(\mathrm{a})$ associated with the constituent apo(a) isoforms. In these studies 28 distinct isoforms were identified, each differing by a single kringle IV unit. Tracking the isoforms through 10 families showed that there could be up to 200 -fold difference in the $L p$ (a) concentration associated with the same-sized isoform produced from different alleles. In contrast there was typically $<\mathbf{2 . 5}$-fold variation in the $\operatorname{Lp}$ (a) concentration associated with the same allele. However, there were four occasions where the concentration associated with a particular allele was reduced below the typical range from one generation to the next. A nonlinear, inverse trend with isoform size was apparently superimposed upon the other factors that determine $L p(a)$ concentration. Inheritance of familial hypercholesterolemia or familial-defective $\mathbf{a p o B}_{100}$ had little consistent effect upon $L_{p}$ (a) concentration. In both the families and in other unrelated individuals the distribution of isoforms and their associated concentrations provided evidence for the presence of at least two and possibly more subpopulations of apo(a) alleles with different sizes and expression. (J. Clin. Invest. 1994. 93:1481-1492.) Key words: apolipoprotein(a) genotyping • apolipoprotein(a) isoforms • apolipoprotein(a) phenotyping • familial hypercholesterolemia • familial defective apolipoprotein $B_{100}$
\end{abstract}

\section{Introduction}

Lipoprotein(a) $[\operatorname{Lp}(a)]^{1}$ is a plasma particle similar in size and lipid composition to LDL, which, in addition to $a p o B_{100}$, contains a second glycoprotein, apo(a), that bears a strong resemblance to plasminogen $(1,2)$. The gene for apo(a) includes multiple copies of a sequence homologous to that which codes for the fourth of the triple-looped, so-called "kringle" structures found in plasminogen (3). Analysis by pulsed-field

Address correspondence to Dr. Brian L. Knight, MRC Lipoprotein Team, Hammersmith Hospital, Ducane Road, London W12 OHS, United Kingdom.

Received for publication 15 August 1993 and in revised form 7 December 1993.

1. Abbreviations used in this paper: $\mathrm{FDB}$, familial-defective $\mathrm{apoB}_{100}$; $\mathrm{FH}$, familial hypercholesteremia; Lp, lipoprotein.

J. Clin. Invest.

(c) The American Society for Clinical Investigation, Inc. $0021-9738 / 94 / 04 / 1481 / 12 \$ 2.00$

Volume 93, April 1994, 1481-1492 electrophoresis has revealed marked heterogeneity in the size of the human apo(a) gene, with evidence for alleles containing anything from 12 to over 40 copies of the kringle IV sequence (4-6). There is also considerable heterogeneity in the apparent size of the apo(a) protein in plasma, as shown by differences in mobility during SDS electrophoresis (7-9). However, apo(a) is a large, highly glycosylated protein and it is technically difficult to establish the presence of discrete size isoforms merely from investigating a general population. In this study we have examined the electrophoretic behaviour of apo(a) isoforms within a number of extended kindred, in order to determine the range of mobilities exhibited by the products of identical alleles, to compare the products of different alleles and to identify unambiguously the different apo(a) size isoforms present.

Generally the concentration of $\operatorname{Lp}(\mathrm{a})$ in plasma is inversely related to the size of its apo(a) component (7). However, there is considerable variation within this trend and family studies $(10,11)$ indicate that plasma $\operatorname{Lp}(\mathrm{a})$ concentrations must be influenced by a variety of inherited factors that are independent of the size of the apo(a) gene. With so many potential heterozygous phenotypes it is unlikely that population studies will be able to provide detailed information about these factors, and even family studies will be of limited value unless it is possible to apportion the total $\mathrm{Lp}(\mathrm{a})$ concentration in each subject accurately between the constituent $\operatorname{Lp}(\mathrm{a})$ species containing the different apo(a) isoforms. In this study we have determined the relationship between isoform size and the signal produced both in the $\mathrm{Lp}(\mathrm{a})$ assay and on apo (a) phenotyping blots, and have established conditions whereby the concentration that can be attributed to each of the $\mathrm{Lp}(\mathrm{a})$ species in a plasma sample can be reliably estimated. We were then able to track the concentration associated with each allele through the families, to compare the values for products of the same and different alleles and to assess the effects of various inherited and environmental factors.

\section{Methods}

Samples. The subjects in this study comprised 169 members of 10 families, 154 unrelated hyperlipidemic patients attending Hammersmith or Charing Cross Hospital Lipid Clinics in London and 51 unrelated normolipidemic subjects drawn from laboratory colleagues and spouses of the patients. A clinical diagnosis of familial hypercholesterolemia (FH) was based on the presence of type II hyperlipidemia, tendon xanthomata, and a family history of premature heart disease. Seven of the families were affected with FH and in all but the AS family, in whom the mutation is not known, the clinical diagnosis was confirmed by analysis of genomic DNA. Two families ( $A E$ and ES) were affected with familial-defective apoB $_{100}$ (FDB), again detected by DNA analysis (12).

Venous blood was collected into tubes containing EDTA and immediately chilled. Plasma was separated by centrifugation within $2 \mathrm{~h}$, divided into $50-\mu 1$ portions, and kept at $-70^{\circ} \mathrm{C}$.

$L p(a)$ assay. Plasma $L p(a)$ concentration was assayed with a Tint Elize Lp(a) immunoassay kit (Biopool AB, Umeå, Sweden; C.V. 3.7\% 
at $25 \mathrm{mg} / \mathrm{dl}$ ) using the standard supplied by the manufacturer. This is a "sandwich" ELISA assay using anti-apo(a) antibodies. With a few selected samples the antibody-coated plates supplied with the kit were also used as the basis for assaying the $\mathrm{apoB}_{100}$ content of $\mathrm{Lp}(\mathrm{a})$. Samples were diluted and the $\operatorname{Lp}(a)$ was bound to the anti-apo(a) on the wells in the same way as for the routine assay. $T$ The $\mathrm{apoB}_{100}$ component was then detected with a rabbit antibody against human $\mathrm{apoB}_{100}$ followed by a peroxidase-conjugated goat antibody against rabbit immunoglobulins. Each incubation was for $1 \mathrm{~h}$ using 1:3000 final dilution of antibodies (Dako Ltd., High Wycombe, UK). Peroxidase activity was assayed using the reagents supplied with the kit and the $\operatorname{Lp}(\mathrm{a})$-apoB content determined by comparison with purified $\mathrm{Lp}(\mathrm{a})$ standards (13). Other apoB-containing lipoproteins at the concentrations found in normal and FH plasma were not detected in this procedure.

Apo (a) phenotyping. Apo(a) phenotype was determined by immunoblotting as described in detail previously (14) with the following modifications. The lyophilized, delipidated samples from $25-\mu \mathrm{l}$ portions of plasma were dissolved in $100 \mu$ l of sample buffer $(2 \mathrm{ml}$ of $5 \%$ SDS with $200 \mu$ l of $\beta$-mercaptoethanol and $300 \mu$ l of bromophenol blue in glycerol) at $100^{\circ} \mathrm{C}$ for $10 \mathrm{~min}$. Proteins were separated in $20 \times 20 \mathrm{~cm}$ vertical $1 \mathrm{~mm}$ thick gels containing $1 \%$ SDS. The running gel was $3 \%$ polyacrylamide containing $0.5 \%$ agarose, poured at $55^{\circ} \mathrm{C}$ between glass plates preheated to $80^{\circ} \mathrm{C}$. The stacking gel was $3 \%$ polyacrylamide, polymerized using UV-illuminated riboflavin as catalyst. The volume of sample added was broadly related to the $\operatorname{Lp}(\mathrm{a})$ concentration of the original plasma ( $50 \mu \mathrm{l}$ for concentrations up to $5 \mathrm{mg} / \mathrm{dl}, 40 \mu \mathrm{l}$ for $5-10$ $\mathrm{mg} / \mathrm{dl}, 30 \mu \mathrm{l}$ for $10-30 \mathrm{mg} / \mathrm{dl}, 20 \mu \mathrm{l}$ for $30-80 \mathrm{mg} / \mathrm{dl}$, and $10 \mu \mathrm{l}$ for concentrations higher than $80 \mathrm{mg} / \mathrm{dl}$ ). Samples were run through the stacking gel at $150 \mathrm{~V}$, then through the running gel at a constant $7 \mathrm{~mA}$ overnight followed by a constant $200 \mathrm{~V}$ for $1 \mathrm{~h}$ after the dye front had reached the bottom of the gel. Proteins were transferred to nitrocellulose membranes and the bands of apo(a) detected as described before (14).

Apportioning the Lp (a) concentration. Developed phenotyping immunoblots were scanned with a Joyce-Loebl Chromoscan III densitometer (Gateshead, UK) using a 530-nm filter. In the majority of cases the density peaks corresponding to the two apo(a) bands were well separated and the area beneath each was determined by automatic integration of the trace between the points of inflexion on either side, taking the intensity at the inflexion point nearer the sample well as background. Where there was no clear separation between peaks the relative areas were estimated manually, either by triangulation or by weighing cut-out traces, with the assumption that the dominant peak was symmetrical. For each sample the areas $\left(A_{1}, A_{2}\right)$ were expressed as a proportion $(M)$ of their sum (i.e., $M_{1}=A_{1} /\left(A_{1}+A_{2}\right)$ etc.). Repeated determinations of the same sample showed that the variation in the estimate of these proportions was 7.7\% for samples on the same gel (SD of 32 observations on three gels). The reproducibility between gels was estimated from scans of the phenotyping standards run on 20 separate gels. The variations in the estimates of the proportions of the two apo(a) bands in each standard (including the close bands in standard D) were not significantly different, with an overall average SD of $12.0 \%$. As described below the proportions derived from immunoblots $(M)$ represent the proportions of the apo(a) molecules present, whereas the assay gives values related to apo(a) protein. Thus the proportion of molecules $(M)$ was converted to a proportion of apo(a) protein $(P)$ using the $\mathrm{Lp}(\mathrm{a}) / \mathrm{apoB}$ ratios $(R)$ appropriate for the isoforms, given by the line in Fig. $4 a$ (i.e., $P_{1}=M_{1} R_{1} /\left(M_{1} R_{1}+M_{2} R_{2}\right)$ etc.). This was then multiplied by the total, assayed, $\operatorname{Lp}(\mathrm{a})$ concentration to give an estimate of the concentration associated with the apo(a) isoform. Dividing by $R$ then gives the concentration as $\operatorname{Lp}(\mathrm{a})$-apoB. Overall the equation reduces to

$\mathrm{Lp}(\mathrm{a})-\operatorname{apoB}_{1}(\mathrm{mg} / \mathrm{ml})=\frac{M_{1}}{M_{1} R_{1}+M_{2} R_{2}} \times \mathrm{Lp}(\mathrm{a})(\mathrm{mg} / \mathrm{dl})$

Apo(a) genotyping. KpnI restriction fragments of genomic DNA were prepared from white blood cells, separated by pulsed-field electrophoresis, blotted and hybridized with a kringle IV probe (MP-1, kindly supplied by Dr. H. Hobbs) essentially as described by Lackner et al. (4). Electrophoresis was performed at $14^{\circ} \mathrm{C}$ in a BioRad CHEF-DRII apparatus (Bio-Rad Laboratories, Richmond, CA) at $180 \mathrm{~V}$ for $30 \mathrm{~min}$ with $4 \mathrm{~s}$ switching followed by $17.5 \mathrm{~h}$ with 6-10-s ramped switching. The size of the fragments was determined by comparison with lambdaphage concatomers (FMC BioProducts, Rockland, ME).

\section{Results}

Identification of apo(a) isoforms. Apo(a) isoforms were separated on $3 \%$ polyacrylamide gels containing $0.5 \%$ agarose to improve their rigidity. Unexpectedly, the mobility of the apo(a) bands in relation to $a_{00} B_{100}$ was greater on these gels than on the $5 \%$ polyacrylamide gels that we had employed before. Thus in these studies we have not related mobility to $a p o B_{100}$, as previously, but as a percentage of that of the fastest of our apo(a) standards. To guard against minor inconsistencies between gels the mobilities of the apo(a) bands were always determined by comparison with known standards run on each gel. The mobilities of these standards are given in the legend to Fig. 1, which shows a gel exhibiting over 15 clearly distinguishable isoforms. Multiple determinations of the same samples on different gels gave values that were within 1 mobility unit of their means (i.e., $\pm 1 \%$ of the mobility of the fastest standard).
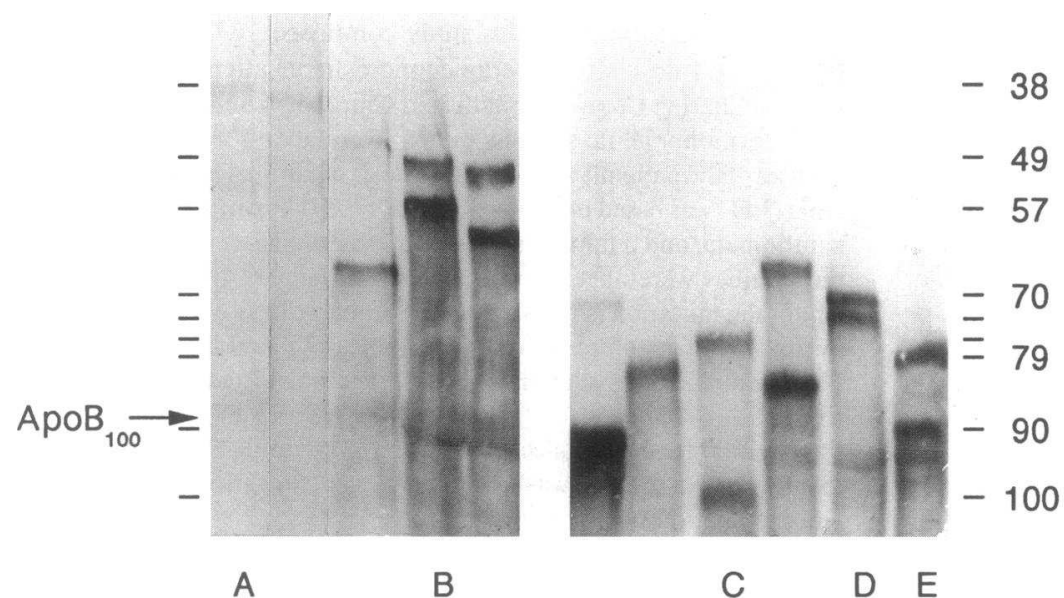

A
B 
The mobilities of the apo(a) isoforms in plasma were determined for 169 members of 10 separate families. Full pedigree diagrams, including apportioned $\mathrm{Lp}(\mathrm{a})$ values, are available on request. Seven of the families were affected with $\mathrm{FH}$ and two with FDB. In all but two cases the inheritance of the apo(a) isoforms followed the expected Mendelian pattern. Only 13 subjects exhibited a single band phenotype, of which two were homozygous for the same-sized isoform. The rest could be explained by the inheritance of one poorly expressed allele (probably coding for the $\mathbf{5 7}$ isoform) in six members of the AS family and one null or poorly expressed allele in four members of the MM family (designated n.d. on the pedigree diagrams). The spread of mobility values for isoforms that were presumed, from qualitative inspection of the immunoblots, to have been derived from the same inherited allele was no greater than that shown for multiple determinations of the same sample.

For each allele in the families, the values of mobility were combined and the means plotted as shown in Fig. $2 a$. These mean values fell into a series of clearly defined groups, the relationship between which was best expressed on a semilogarithmic plot. The points formed a smooth curve if the mean mobility of each group, plotted as a logarithm, was separated from the next by one, or in some cases two, linear units (Fig. 2

\section{a). Family isoforms}

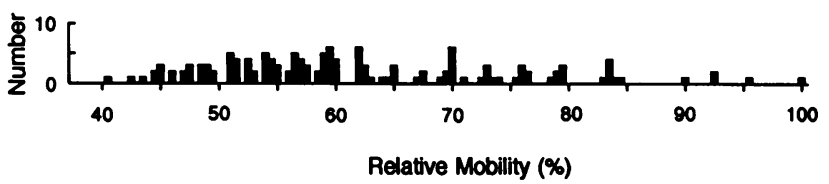

b). Relationship between family isoforms

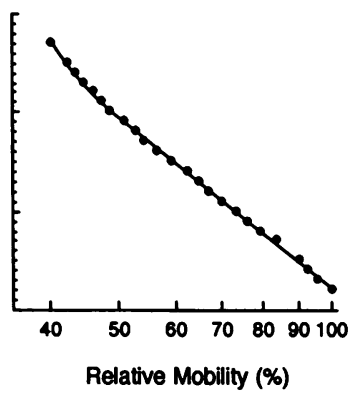

c). Population isoforms

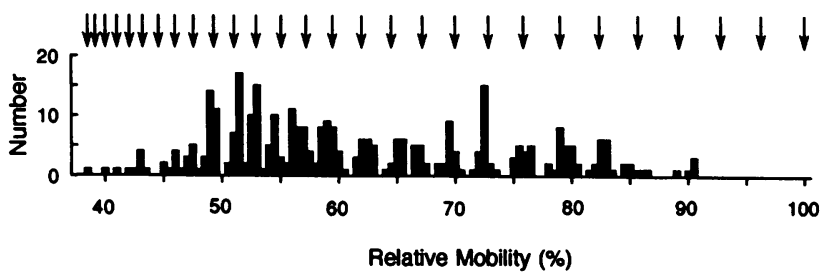

Figure 2. Electrophoretic mobility of apo(a) isoforms from different alleles. ( $a$ ) Mean values of relative mobility for the products of each apo(a) allele in the families. ( $b$ ) Values in each group of isoforms in the families were combined and the means plotted as a logarithm against an arbitrary linear scale. (c) Relative mobility of apo(a) isoforms in the hyperlipidemic and normal subjects (see Methods). The arrows indicate the mobilities of the predicted isoforms derived from the line in $b$. $b$ ). The line describing the curve was used to calculate a consensus mobility for each isoform, shown as the arrows in Fig. 2 $c$. This figure also demonstrates the mobilities of the isoforms observed in a more general population. The values again fell into discreet groups which generally coincided with the consensus mobilities obtained from the isoforms in the families. The two isoforms presumed to be missing from the families were observed in this population, as well as one predicted to be two units larger. In all there was evidence for 28 apo(a) isoforms, progressing in size by the same sized unit. For current purposes each isoform is referred to by its mobility, rounded to the nearest whole number.

Genomic DNA from selected subjects exhibiting a range of phenotypic isoforms was subjected to pulsed-field electrophoresis after digestion with Kpnl. The fragments, containing the repeated kringle sequences, were detected by Southern blotting and hybridization with a human apo(a) kringle IV probe. Assuming in each case that the larger isoform was the product of the larger gene, the size of the DNA fragment was directly related to the isoform observed in plasma (Fig. $3 c$ ). The slope of the line indicated that each isoform was separated by a unit that corresponded to $5.6 \mathrm{~kb}$ of genomic DNA.

Apportioning the plasma $\operatorname{Lp}(a)$ concentration. The easiest way to estimate the concentration of $\operatorname{Lp}(a)$ associated with the two apo(a) isoforms in a given subject would be to apportion the total $\mathrm{Lp}(\mathrm{a})$ concentration assayed in plasma according to the proportion of each isoform determined from densitometric scans of the immunoblots used for phenotyping. However, a direct calculation is unlikely to be accurate, since unreduced $\mathrm{Lp}(\mathrm{a})$ is used in the assay and reduced, unfolded apo (a) for the immunoblots. Thus different antigenic determinants will be exposed in the two procedures and it cannot be assumed that the relationship between apo(a) size and the signal produced will be the same for each. To examine this, samples were selected that had a reasonably high $\operatorname{Lp}(\mathrm{a})$ concentration in plasma ( $>8 \mathrm{mg} / \mathrm{dl}$ ) and in which essentially all the apo(a) was present in a single isoform. Each plasma sample was assayed for $L p(a)$ using the standard assay kit, which detects the apo(a) component. They were also assayed for the $a^{2} B_{100}$ component with an ELISA procedure employing anti-Lp(a) as the capture antibody and anti-apoB $\mathrm{B}_{100}$ as the detecting antibody. The ratio of the values for $L p(a)$ to those for $L p(a)$-apoB fell linearly as the size of the apo (a) component decreased (Fig. $4 a$ ). One sample was selected for each isoform and portions containing equal amounts of $L p(a)-a p o B$ were run on the normal phenotyping gels. The intensity of the apo(a) bands detected, determined by densitometric scanning, was essentially unaffected by the size of the apo(a) isoform (Fig. $4 b$ ).

The effect of $\operatorname{Lp}(a)$ concentration on the response of the blotting procedure was determined by running different sample volumes on the gels (Fig. 5). In each case, covering a wide range of band intensities, the signal produced was directly related to the amount of sample applied, up to at least $2 \mu \mathrm{g}$ of $\mathrm{Lp}$ (a) per lane (Fig. $5 a$ ). Importantly, in more typical samples where two isoforms were detected, the ratio of the intensities remained constant as the concentration varied (Fig. $5 b$ ).

From these observations it can be concluded that the ratio of the intensities of the bands observed on the phenotyping immunoblots will give a reliable estimate of the proportion of the apo(a) molecules present in the original sample, independent of their size, and to apportion the total $\operatorname{Lp}(\mathrm{a})$ concentration correctly this proportion should be adjusted to take into 
a)

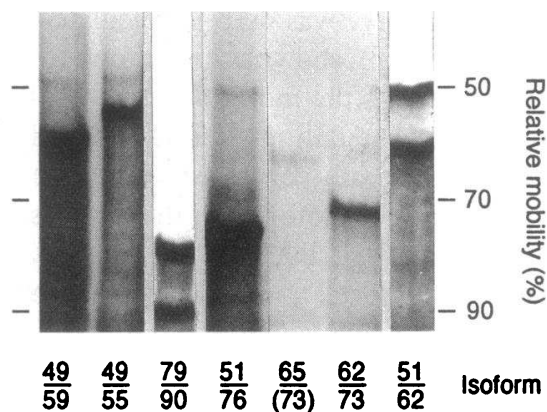

b)

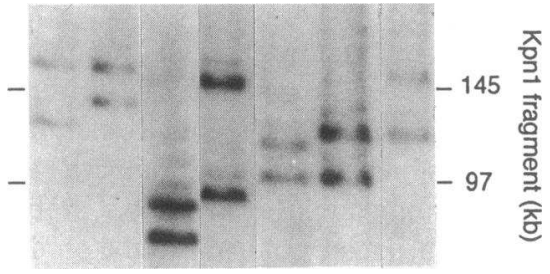

c)

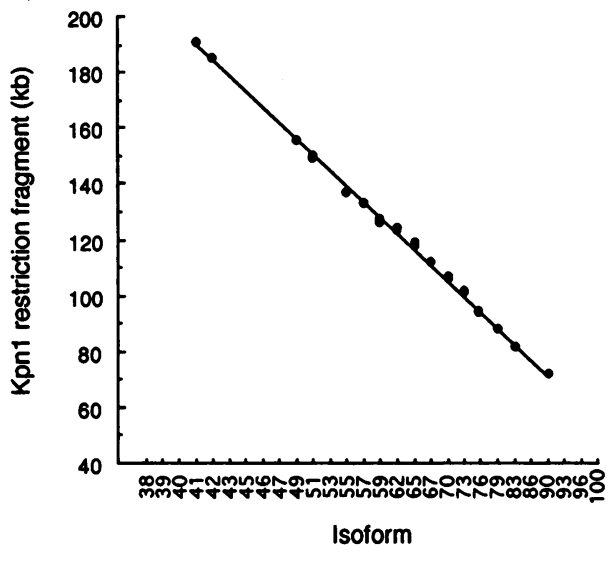

(\% mobility of most rapidly migrating isoform)

Figure 3. Relationship between apo(a) isoform and allele size. (a) Phenotyping blot of plasma samples containing the apo(a) isoforms indicated beneath (some overloaded to visualize the minor bands). (b) Kpnl restriction fragments of genomic DNA from the same subjects. Fragments were separated by pulsed-field electrophoresis and detected after Southern blotting with probe MP-1. (c) The size of the $\mathrm{Kpn} 1$ fragments, determined by comparison with lambda-phage concatomers, related to the apo(a) size isoform detected in plasma.

account the different response of the assay to $\operatorname{Lp}(\mathrm{a})$ containing apo(a) of different sizes. This was achieved using the line describing the points in Fig. $4 a$, as described in detail in the Methods section.

$L p($ a) concentrations associated with different apo(a) alleles. For each of the family members the plasma $\mathrm{Lp}(\mathrm{a})$ concentration was apportioned as described. It was immediately obvious that although there was a general inverse trend between isoform size and its associated $\operatorname{Lp}(a)$ concentration, the relationship was not by any means absolute. For instance, in the LD family (Fig. 6), the concentration of the smaller 90 species was much lower than that of the larger 73 species. Similarly, in the DL family the concentration of the 55 species was over 10-fold higher than that of the smaller 76 species or of the similarly-sized 57 and 53 species (Fig. 6).

\section{a). Assay}

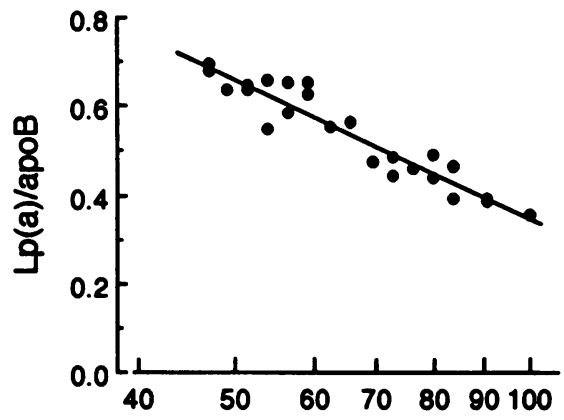

b). Immunoblotting

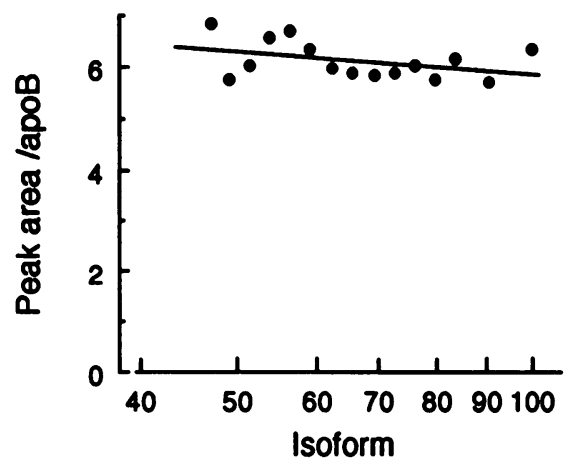

(\% mobility of most rapidly migrating isoform)

Figure 4. Response of $\operatorname{Lp}(\mathrm{a})$ assay (a) and phenotyping blots (b) to apo(a) size. (a) Plasma samples containing essentially single apo(a) isoforms were assayed for $\mathrm{Lp}(\mathrm{a})$ content using the standard kit and for $\mathrm{Lp}(\mathrm{a})-\mathrm{apoB}_{100}$ content using a modified form of the kit as described in Methods. Values for $\mathrm{Lp}(\mathrm{a})(\mathrm{mg} / \mathrm{dl})$ are expressed relative to the corresponding $\mathrm{Lp}(\mathrm{a})-\mathrm{apoB}_{100}$ content $(\mu \mathrm{g} / \mathrm{ml})$. The equation of the line of best fit was $\operatorname{Lp}(a) /(\operatorname{Lp}(a)-a p o B)=2.42-1.04 \log _{10}$ (isoform relative mobility). (b) One single-isoform sample was selected for each size and 30- $\mu$ l portions containing $150 \mathrm{ng}$ of $\mathrm{Lp}(\mathrm{a})$ apoB were subjected to the standard phenotyping procedure. Values shown are the area (arbitrary units) under the apo(a) density peaks obtained by scanning the developed blots, and are the averages of results from two separate gels, each containing all the samples.

A consistent pattern could be seen throughout the families. Products of different alleles coding for the same-sized apo(a) proteins were present at widely different concentrations. In contrast, the concentrations of products of identical alleles showed a much smaller variation. This is clearly illustrated in the AS family (Fig. 6). The $\mathrm{Lp}(\mathrm{a})$ concentration associated with the 76 isoform present in five siblings (nos. 27, 13, 4, 11, and 20) varied $\sim 2.5$-fold over the range 69-154 $\mu \mathrm{g}$ of $\mathrm{Lp}(\mathrm{a})$ $\mathrm{apoB} / \mathrm{ml}$. This was $\sim 10$-fold higher than the concentration associated with the same-sized 76 isoform introduced with subject AS8. Likewise in the JK family (Fig. 6) the concentration associated with the same 57 species varied over a 2.5 -fold range, whereas those associated with the different 51 species differed over 25 -fold. Numerous similar examples can be seen in Fig. 7, which shows the values for each identified allele in the families studied.

In the great majority of cases the concentration of the $\operatorname{Lp}$ (a) species followed the inheritance of the apo(a) allele. Again taking the AS family as an example (Fig. 6), the 79 allele 

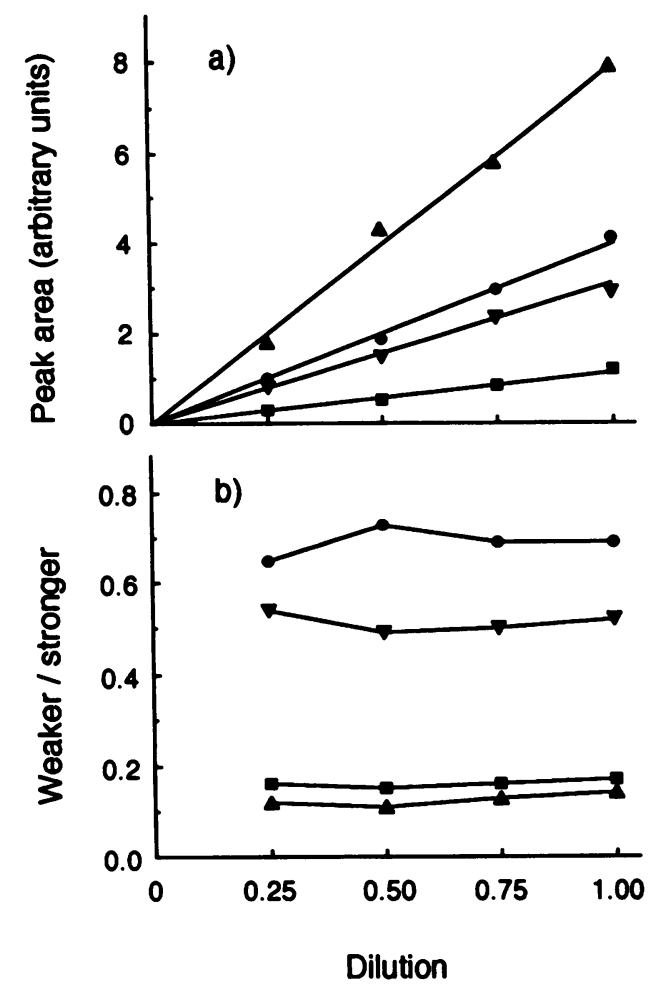

Figure 5. Quantitation of apo(a) band density on immunoblotting. Plasma samples were lyophilized, delipidated and resuspended in 100 $\mu l$ of sample buffer. Portions were diluted to $0.75,0.5$, and 0.25 of the original concentration using similarly treated lipoprotein-deficient serum as diluent. For each sample the same volume of each dilution was subjected to the standard immunoblotting procedure and the densities of the apo(a) bands determined by scanning. Samples used were: $(i)(\bullet)$ phenotype $100 / 76, \mathrm{Lp}(\mathrm{a})$ concentration $90 \mathrm{mg} / \mathrm{dl}, 10$ $\mu \mathrm{l}$ applied; (ii) ( $\bullet$ ) phenotype 57/49, $20 \mathrm{mg} / \mathrm{dl}, 32 \mu \mathrm{l}$ applied; ( $i i i)$ (A) phenotype $83 / 53,59 \mathrm{mg} / \mathrm{dl}, 16 \mu \mathrm{l}$ applied; (iv) ( $\nabla$ ) phenotype $70 / 57,16 \mathrm{mg} / \mathrm{dl} 32 \mu \mathrm{l}$ applied. (a) Density of the stronger bands of samples $i(100$ isoform, $\bullet)$ and $i i i(83$ isoform, $\Delta)$ and weaker bands of samples $i i$ (45 isoform, $\square$ ) and iv (70 isoform, $\nabla$ ). (b) Ratio of the density of the weaker to that of the stronger band.

present in subject 19 was expressed at a similarly high concentration over the next three generations; the high-concentration 76 isoform in subject AS 19 was inherited over the next two generations and the low-concentration 76 isoform in subject AS8 by his son.

To obtain some indication of the typical spread of concentrations associated with a given allele, the values observed for the same allele in different individuals were combined. For this purpose, unaffected subjects and those affected with FH or FDB were treated separately. Where there were three or more comparable values each was expressed as a percentage of the median (Fig. $8 a$ ) and where there were only two they were expressed as a percentage of their mean (Fig. $8 b$ ). In both cases the great majority of values fell within $50 \%$ and $150 \%$ of the median or mean, in a population with a standard deviation of $\sim 21 \%$. Only two of the pairs were outside this range and five of the values $<50 \%$ of the median. These are marked on the pedigree diagrams in Fig. 10 and were excluded from subsequent calculations.

Effect of FH and FDB. Nine of the families used in this study are affected with FH or FDB and after apportioning the $\mathrm{Lp}$ (a) concentration it was possible to examine the effects of these disorders on the products of individual alleles. The results in the FH families were inconsistent. For instance, in the AS family (Fig. 6) the $\operatorname{Lp}(\mathrm{a})$ concentration associated with the 76 allele showed little difference between the four FH subjects (nos. 27, 1, 11, and 20, mean $112 \mu \mathrm{g} / \mathrm{ml}$ ) and the three non-FH subjects (nos. 19, 13, and 18 , mean $102 \mu \mathrm{g} / \mathrm{ml}$ ), whereas in the JK family values for the 57 allele in the FH subjects (nos. 1, 12, 3 , and 6 , mean $30.1 \mu \mathrm{g} / \mathrm{ml}$ ) were above those of the normals (nos. 5 and 4 , mean $17.5 \mu \mathrm{g} / \mathrm{ml}$ ). In total, there were 24 instances where a comparison could be made between alleles expressed in non-FH and heterozygous FH individuals and 10 between normal and FDB individuals. The mean values for the affected subjects were expressed as a ratio of the mean for the corresponding unaffected subjects (Fig. 9). In all but two cases, where the ratios were exceptionally high ( 9.3 for the 51 allele in the MM family and 4.6 for one 59 allele in the TH family, Fig. 10 ), they fell within the range that could be explained by the observed $50-150 \%$ variation in the expression of a given allele. Overall (excluding the two exceptional values) the ratios were $1.15 \pm 0.08$ ( $\mathrm{SE}$ of 21 values) for heterozygous $\mathrm{FH}$ to non-FH subjects and $0.98 \pm 0.11$ (SE of 10 values) for FDB to non-FDB subjects. Neither ratio was significantly different from $1.0(P$ $>0.05$ ).

If there were a significant effect of $\mathrm{FH}$ upon the plasma concentration of $\operatorname{Lp}(a)$ it might be expected to be most pronounced in homozygous individuals. In the families described here there are seven such subjects that are informative, but again there was no consistent effect upon $L p(a)$ concentration. All the values in homozygous FH individuals were within the typical range, except for the 51 allele in TH7, which was only a quarter of that of her father (TH4) (Fig. 10).

Atypical values. There were 10 occasions, outlined above, when the $\operatorname{Lp}(\mathrm{a})$ concentration associated with an allele was outside the apparently typical range. These and the relevant parts of the pedigrees are shown in Fig. 10. Unfortunately in many cases there was too little information to establish whether the product of the other allele in the same subject was also affected. If, as is probable, it is assumed that their siblings have inherited identical alleles, it can be concluded that both alleles were poorly expressed in subjects MM43, KE7, and AE18. This possibility cannot be excluded for subjects MM79 and TH9. Similarly it is possible that both alleles were overexpressed in subject ES7. However, there can be no such explanation for the atypical concentrations associated with one of the alleles in subjects TH7, MM36, MM5, or MM6, in whom the expression of the other allele was within the expected range. In each case there was a reduction in concentration from one generation to the next.

$L p(a)$ concentration associated with different apo (a) alleles. The $\mathrm{Lp}(\mathrm{a})$ concentration associated with the apo(a) alleles identified in the families is shown in Fig. $11 a$. A clearer indication of the range of values was obtained using a logarithmic scale, along which the expected 3-fold variation in observed expression of identical alleles would remain constant. On this scale (Fig. $11 b$ ) there was a generally inverse linear progression of $\mathrm{Lp}(\mathrm{a})$ concentration with apo(a) isoform size. For each apo (a) isoform there was a 10-150-fold difference in values, the range being greater for the larger apo(a) isoforms than for the smaller. There were two areas where there appeared to be a greater density of points, shown as the shaded areas in Fig. $11 b$. In both these clusters the points for each 

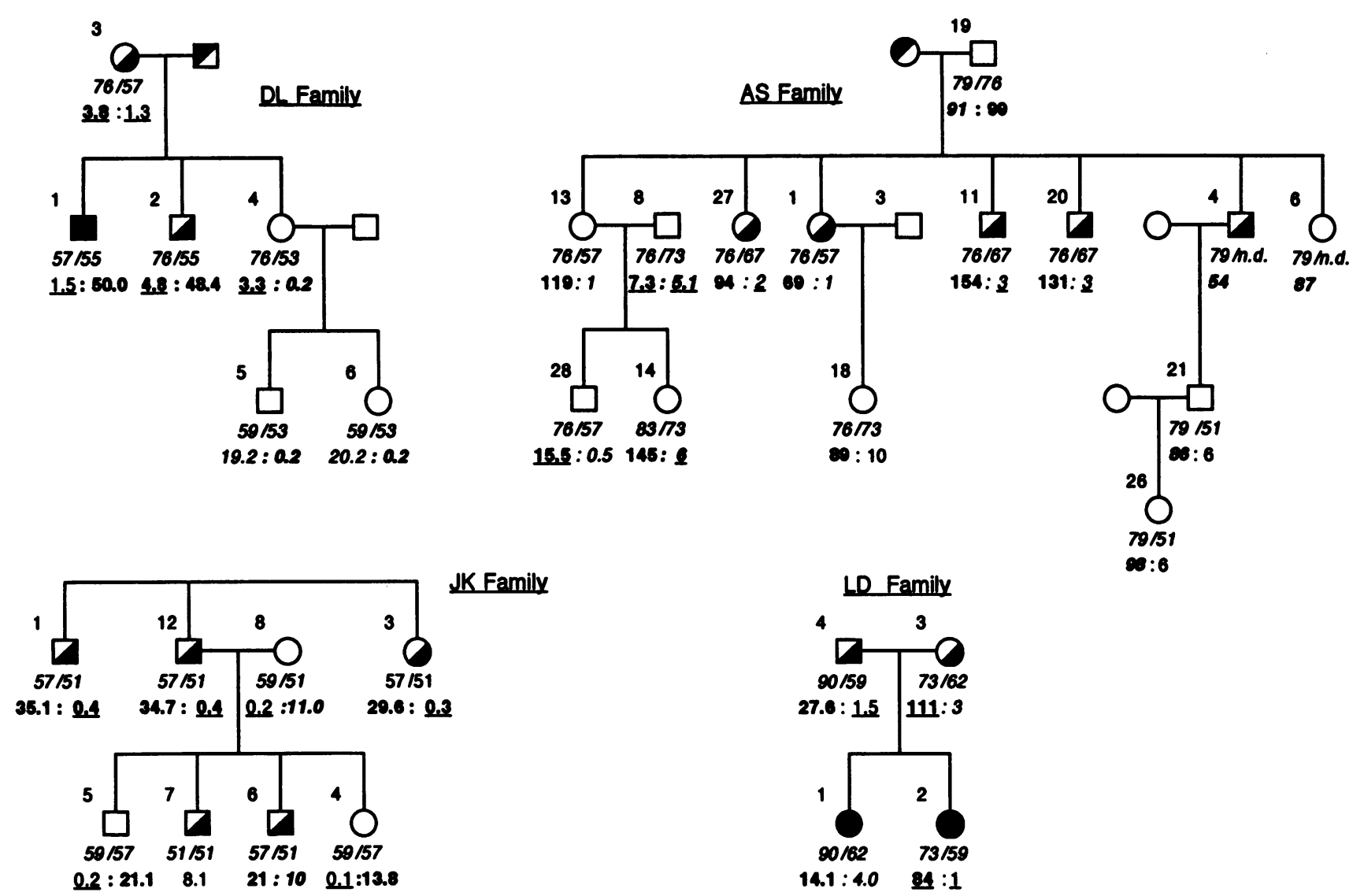

Figure 6. Variation in $\mathrm{Lp}(\mathrm{a})$ concentration associated with the same apo(a) allele. The whole available pedigrees are shown for the DL and LD families. The diagrams of the JK and AS families have been simplified to illustrate the range of $\mathrm{Lp}(\mathrm{a})$ concentrations associated with various apo(a) alleles described in the text; complete diagrams are available on request. Heterozygous FH subjects are represented by half-blacked symbols and homozygous FH subjects as fully blacked symbols. Apo(a) phenotype is shown in italics under the symbols, with the apportioned plasma $\mathrm{Lp}(\mathrm{a})$-apoB concentration $(\mu \mathrm{g} / \mathrm{ml})$ beneath the associated isoform. Within each family values for the products of the same allele in different individuals are shown in the same typeface (bold, italic, or underlined). Single uninformative values are in plain text.

isoform were contained within a 3-4-fold range and each was above the exponential line of best fit. In contrast, the values below the line resulted from a more diffuse spread of isoforms.

To discover whether the clustering of points was of more general significance, the $\operatorname{Lp}(\mathrm{a})$ concentration was apportioned between the apo (a) isoforms for 154 unrelated subjects attending Lipid Clinics in London, who might be expected to exhibit a preponderance of the highly expressed alleles of interest. Values for subjects with a clinical diagnosis of heterozygous FH were separated from those of subjects who were hyperlipidaemic but not FH. Both groups exhibited a similar pattern of points (Fig. 12, $a$ and $b$ ), and the exponential lines of best fit were virtually identical, both to each other and to the line derived from the values in the families. Again there were two apparent populations of isoforms with values above the line and a greater spread with values below. Values for a limited selection of normal subjects (Fig. $12 c$ ) were more evenly distributed, although some clustering of points was still apparent. There was a smaller proportion of the small isoforms associated with the highest $\mathrm{Lp}(\mathrm{a})$ concentrations in the normal subjects, but in this case there was an indication that there could be more than one population with values below the line. Fig. 13 shows the total numbers of each isoform in all of the samples studied, separated into those with associated $\mathrm{Lp}(\mathrm{a})$ -
apoB concentrations above and below the exponential line of best fit observed for the families. Those with values above the line fell into at least two distinct populations, while those with values below the line showed no clear evidence for more than a single population, though the possibility of more cannot be excluded.

\section{Discussion}

The method used in this study for separating apo(a) isoforms was a refinement of standard procedures, with $0.5 \%$ agarose added to provide rigidity to $3 \%$ polyacrylamide gels and a number of improvements to the preparation of the samples. Sensitivity was such that two isoforms could be detected in $94 \%$ of subjects in a general population, suggesting a frequency of $<3 \%$ for any null allele. When using known samples as standards the method gave consistent values for apo(a) mobility with an error that was usually well within the span observed for the different isoform groupings.

The apo (a) alleles were tracked through a number of families on the assumption that the inheritance of apo(a) isoforms of the same mobility reflected the inheritance of the same allele. This is a common assumption which is supported by the 

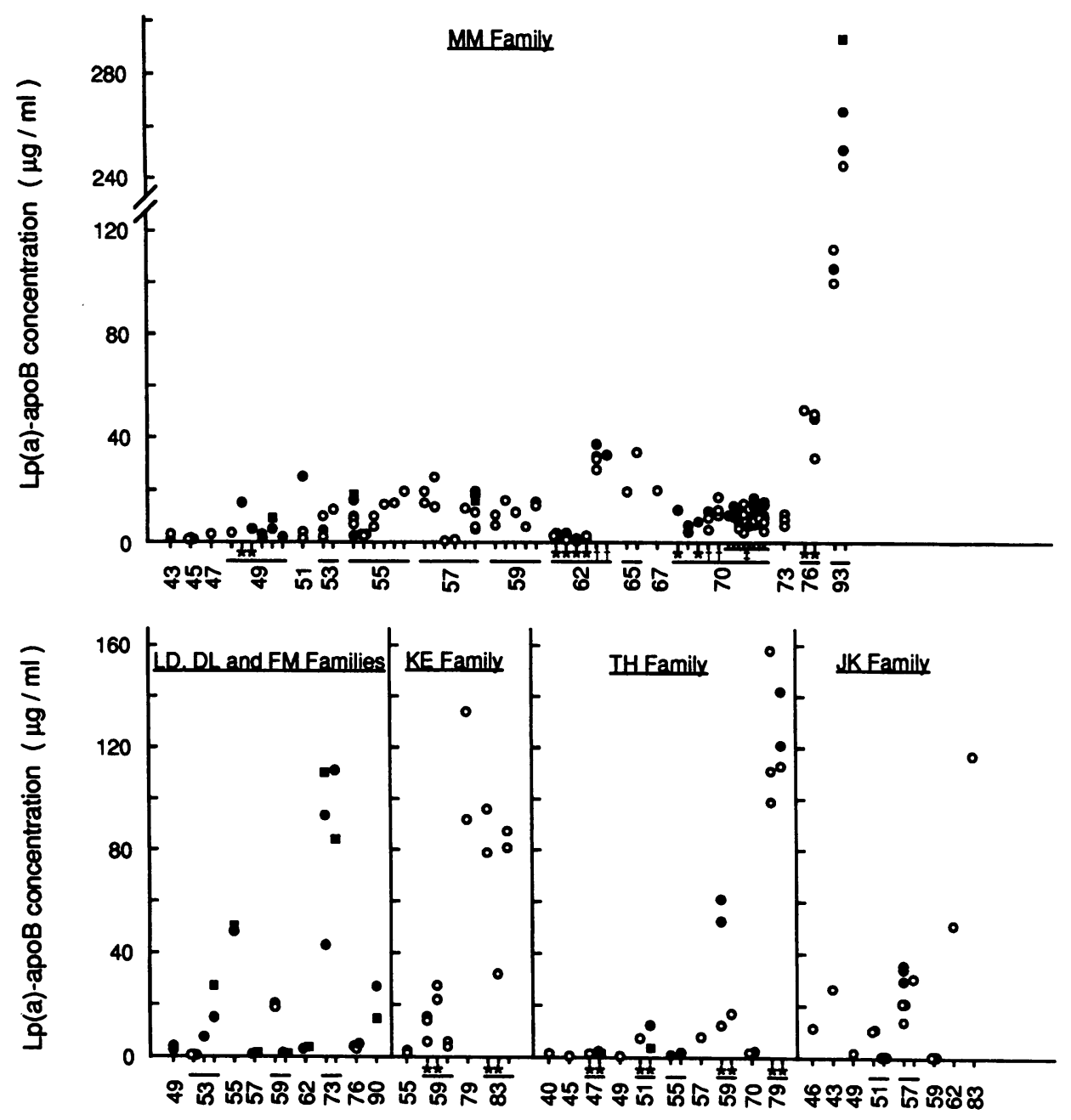

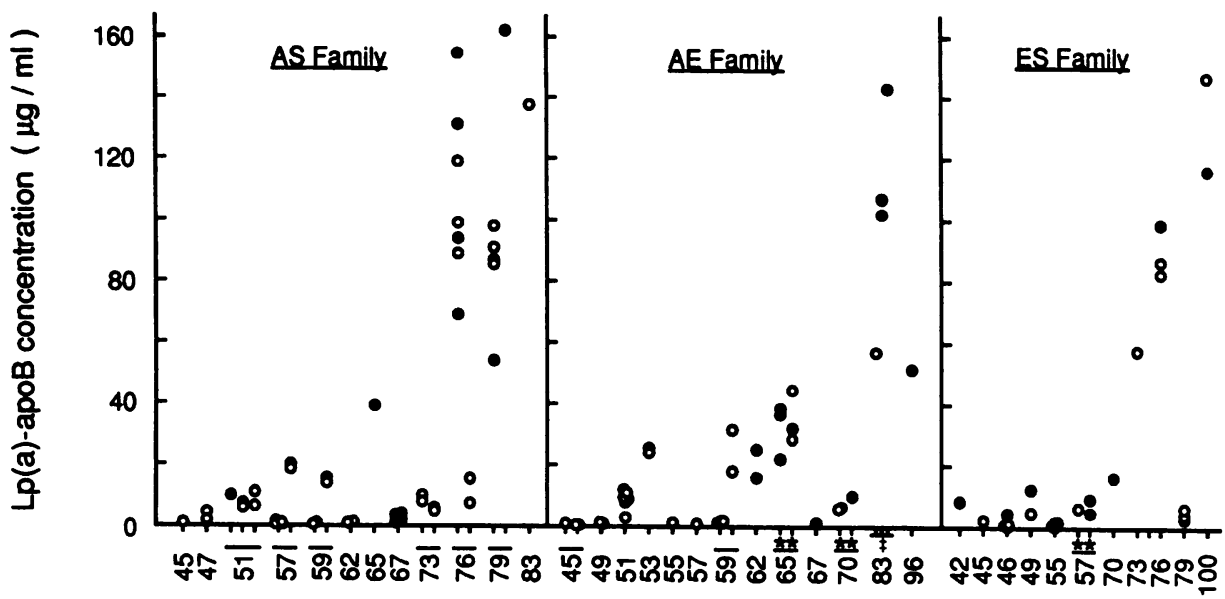

Isoform
Figure 7. Lp(a) concentration associated with each apo(a) allele in the families. Apportioned values for $\mathrm{Lp}(\mathrm{a})$-apoB concentration are given for the different apo(a) alleles in each family. The symbols represent values for heterozygous FH or FDB (AE and ES families) subjects ( $\bullet$ ), homozygous FH subjects ( $(\bullet)$ or unaffected subjects $(0)$. Symbols * or $\dagger$ indicate alleles that are possibly identical. $\ddagger$ indicates values derived from the same or at most two alleles. general correspondence that has been observed between isoform mobility and the size of the genomic DNA fragment containing the Kringle IV repeats in subjects apparently homozygous for the same-size allele (4). On this basis the inheritance of the apo(a) alleles through the families followed the expected pattern in all but two cases, where there had been apparent recombination.
The mean mobility values for the products of the alleles in the families fell into discrete groups rather than a broad continuum, confirming the presence of specific isoforms. The spacing between the groups indicated that most were separated by the same-sized unit, which was shown to correspond to $5.6 \mathrm{~kb}$ of genomic DNA, the size of a single kringle IV repeat (4). There was no evidence for isoforms separated by less than a whole 

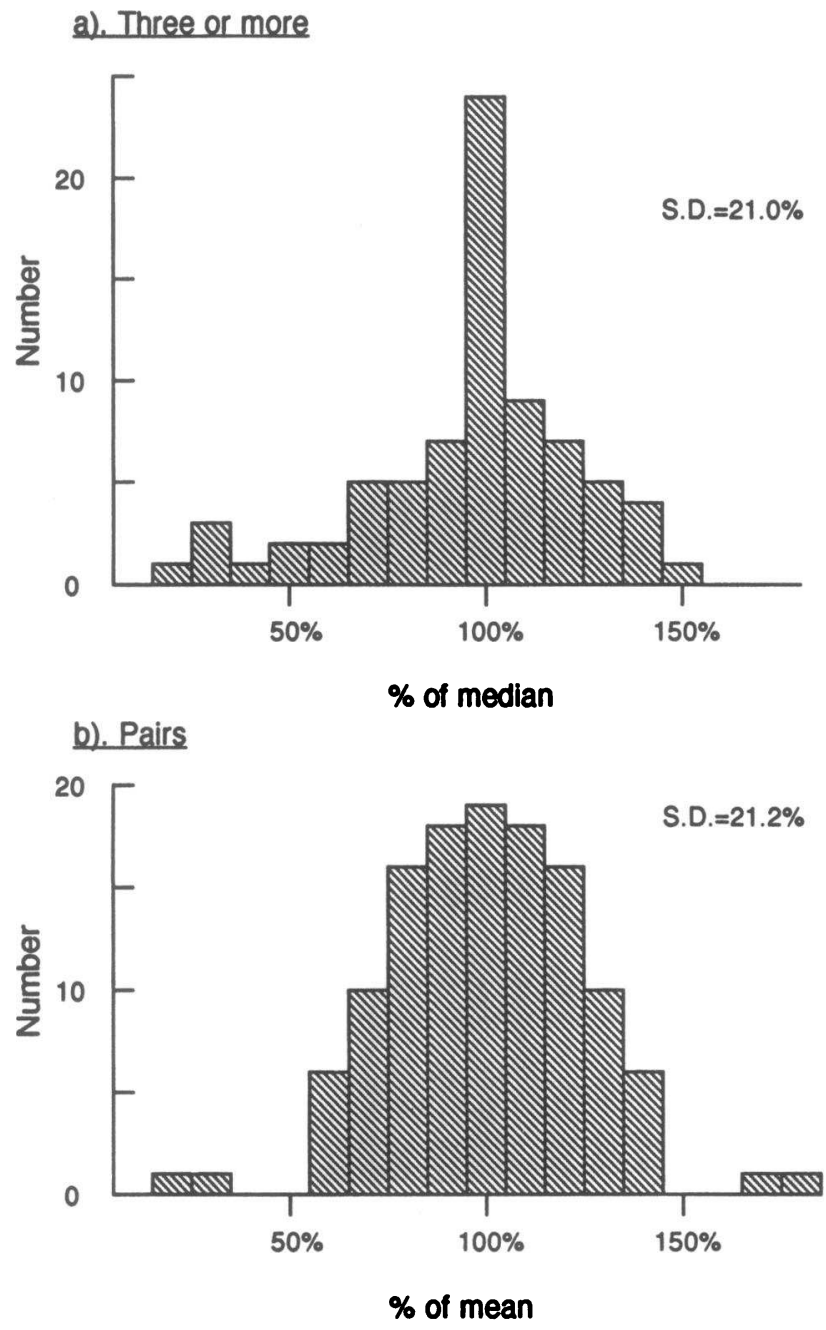

Figure 8. Spread of plasma $\mathrm{Lp}(\mathrm{a})$ concentrations associated with the same apo(a) allele. Apportioned values for $\operatorname{Lp}(\mathrm{a})$-apoB concentration associated with the same apo(a) allele in similarly affected individuals were expressed as a percentage of their median ( 3 or more) or mean (pairs). Values for unaffected individuals and for those affected with heterozygous FH or FDB were treated separately. Homozygous FH subjects were not included. SD calculations excluded the values below $50 \%$ of the median $(a)$ and the two extreme pairs $(b)$.

kringle IV unit, nor for any minor differences in electrophoretic mobility related to differences in glycosylation. Overall, 28 consecutive isoforms were observed. Lackner and Hobbs (5) have reported that an allele containing 12 kringle IV repeats produced a Kpn 1 restriction fragment of $42 \mathrm{~kb}$, from which it can be predicted that the isoforms identified in our samples contained between 14 and 41 kringle IV units. In these studies we have resisted the temptation to number the apo(a) isoforms, preferring to identify them at this stage by a figure related to mobility. Eventually some common nomenclature will need to be adopted, the simplest of which would be by the number of kringle IV repeats present. Although this can be determined for the apo(a) alleles there is still too little information for such a nomenclature to be universally applied to the apo(a) isoforms themselves. There was an exact correspondence between isoform mobility and allele size in the few samples that we have compared, but it will be important to confirm

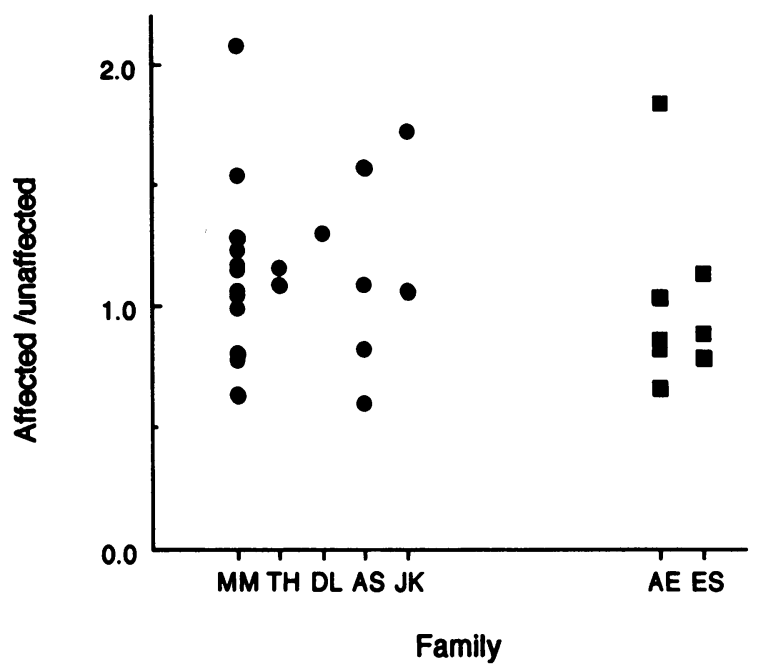

Figure 9. Effect of FH ( $\bullet$ ) or FDB ( $\bullet$ ) on Lp(a) concentration. In instances where unaffected and heterozygous FH or FDB subjects had inherited the same apo(a) allele, the apportioned $\mathrm{Lp}(\mathrm{a})$-apoB concentration for the affected individuals (mean or single as appropriate) was expressed as a ratio of that for the unaffected individuals. The mean $( \pm \mathrm{SE})$ ratio was $1.15 \pm 0.08$ for the FH subjects and $0.98 \pm 0.11$ for the FDB subjects.

this over a much wider range of samples from different ethnic populations.

An advantage of phenotyping over genotyping is that the blots can be used to provide information about $\operatorname{Lp}(\mathrm{a})$ concentrations. In this paper we have described the way in which the $\mathrm{Lp}(\mathrm{a})$ concentration in plasma can be apportioned between the constituent apo(a) isoforms. This could not be achieved accurately simply from densitometric scans of the blots since the assay responded to the amount of apo(a) protein present and the immunoblotting to the number of apo(a) molecules. Because of uncertainties over the standard supplied with the assay the apportioned values have been presented as $\operatorname{Lp}(a)$ apoB concentration, which is a measure of the number of $\mathrm{Lp}$ (a) particles. It is not yet known if the deleterious effects of $\operatorname{Lp}(\mathrm{a})$ are related to the number of particles present or to the number of kringles. If particles are more important, assays based on the recognition of repeated elements could give misleading values without knowledge of the isoform sizes.

In the majority of cases the concentration of $\operatorname{Lp}(a)$ associated with the same allele expressed in different subjects was contained within a 3-fold range, in a population with an SD of $21 \%$ of the mean. In these family studies both $L p(a)$ concentration and phenotyping were performed in duplicate, which reduces the error in the determination of the apportioned values to 9\% (SD). Thus much of the variation can be attributed to differences between individuals. Although not large in relation to the overall range, this variation (SD of $19 \%$ of the mean) suggests that factors outside the apo(a) gene locus can have a significant influence upon $L p(a)$ concentration. Since $L p(a)$ contains apo $\mathrm{B}_{100}$, one of these factors could be the disruption of the interaction between LDL receptors and their ligand through the inheritance of FH or FDB. Previous studies have shown little effect of $\mathrm{FH}$ upon plasma $\mathrm{Lp}(\mathrm{a})$ concentrations, but these were limited to comparing affected and unaffected siblings who had inherited the same $\operatorname{Lp}(a)$ phenotype (14). 

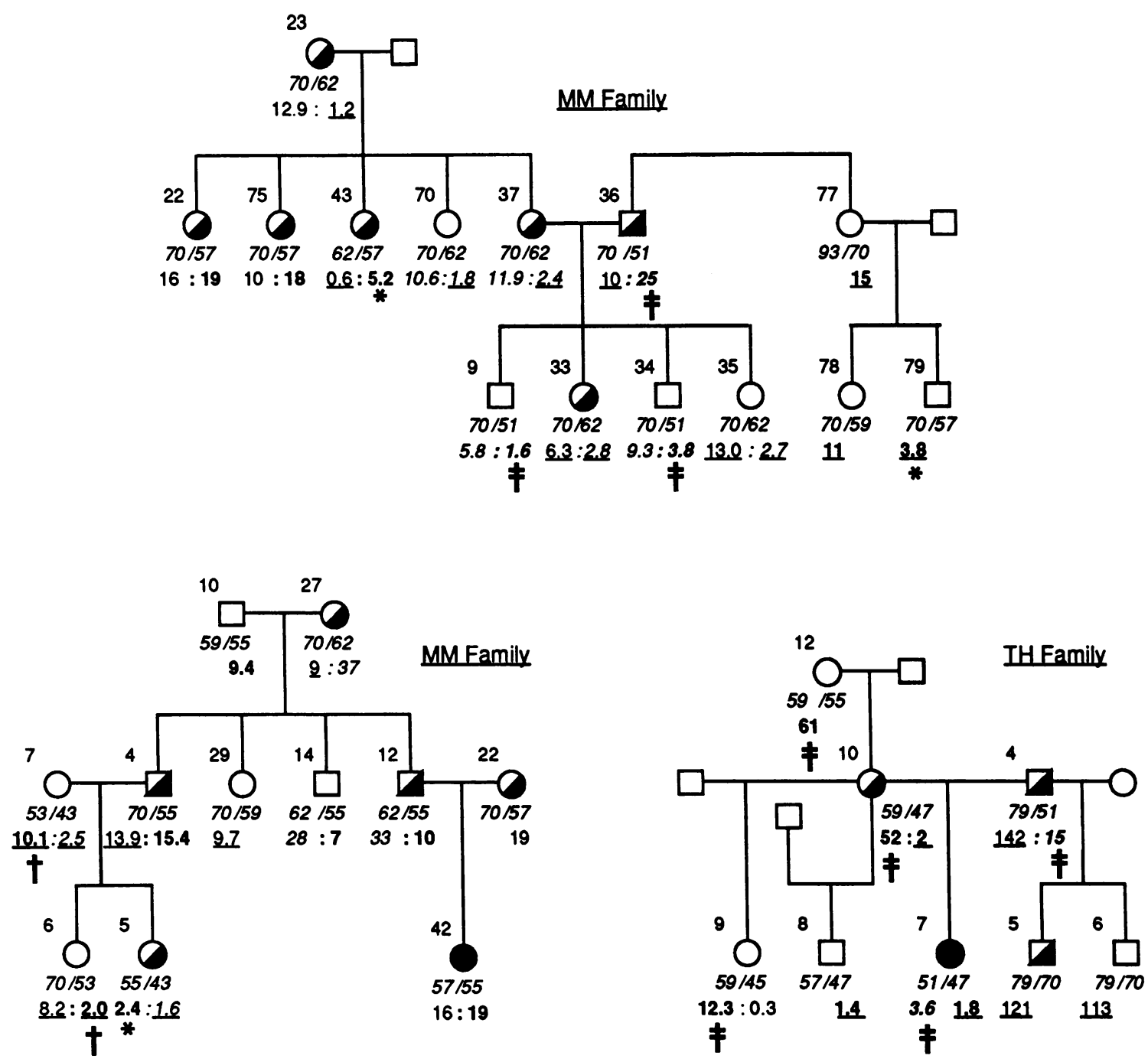

AEFamily
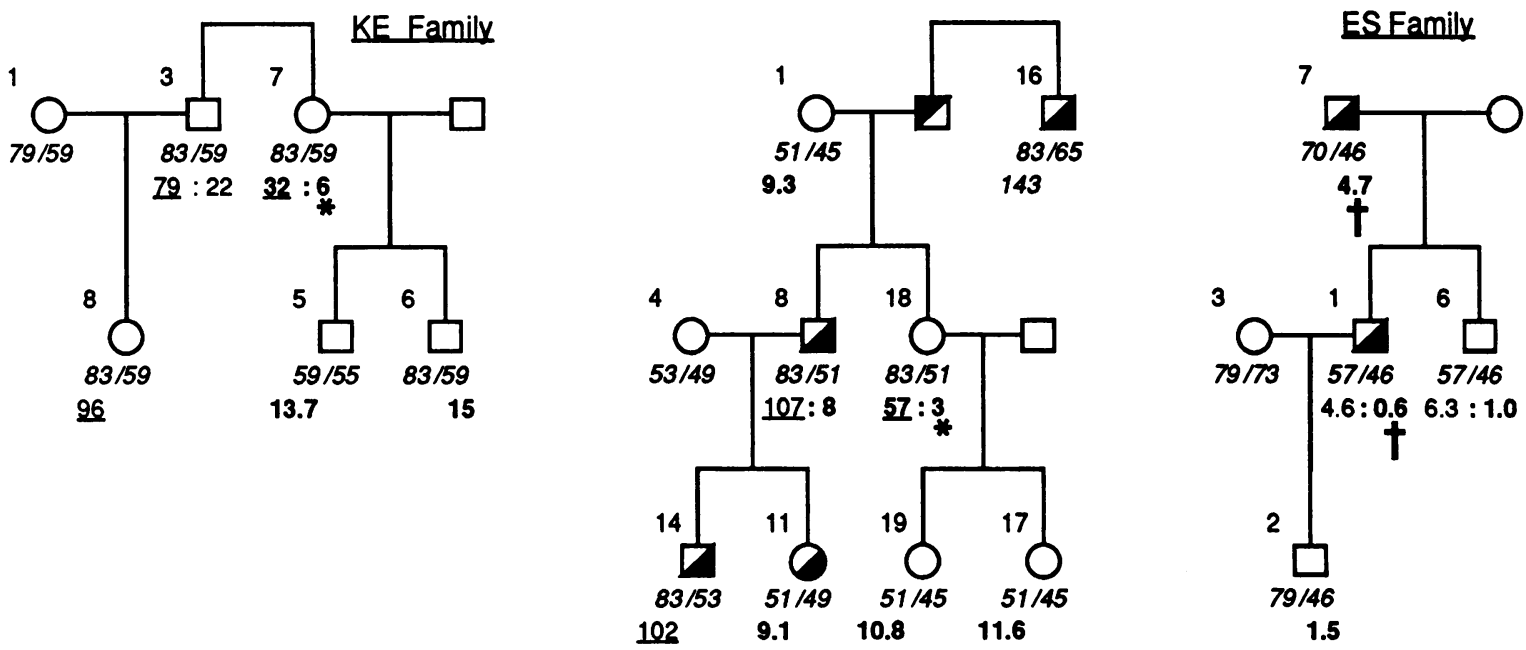

Figure 10. Simplified pedigree diagrams illustrating the atypical Lp(a) values. Heterozygous FH or FDB (AE and ES families) subjects are represented by half-blacked symbols, and homozygous FH subjects by fully blacked symbols. Apo(a) phenotype is shown in italics immediately under the symbol with the associated $\mathrm{Lp}(\mathrm{a})$-apoB concentration $(\mu \mathrm{g} / \mathrm{ml})$ beneath. Within each diagram values for the products of the same allele in different individuals are shown in the same typeface (plain or bold, italic or underlined). For clarity, uninformative values have been omitted. ${ }^{*}$ The five values below $50 \%$ of the median for those in similarly affected individuals, as shown in Fig. 8 a. ${ }^{\dagger}$ The values outside $50-150 \%$ of the means in similarly affected individuals, as shown in Fig. $8 b .{ }^{\ddagger}$ Values that differ by more than threefold between affected and unaffected individuals (MM and TH families) or homozygous and heterozygous FH individuals ( TH family). 

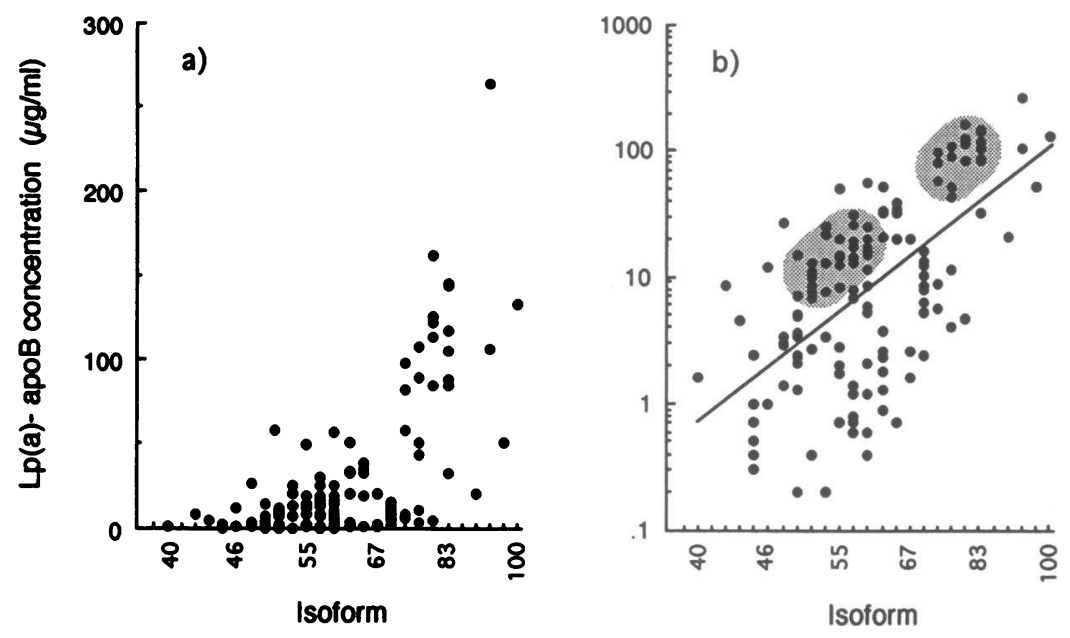

Figure 11. Mean $\mathrm{Lp}$ (a)-apoB concentrations associated with each apo(a) isoform in the families. The mean apportioned $L p(a)$-apoB concentration was calculated for each apo(a)-allele product. Values for affected and unaffected subjects were combined. The atypical values were not included. The points are shown on a linear scale $(a)$ and a logarithmic scale $(b)$, with the exponential line of best fit. Areas where there was apparent clustering of points are shaded. The vertical width of the shaded areas represents a fourfold difference in concentration.

Seven of our families were affected with FH (defective LDL receptors) and two with FDB (binding-defective apoB), and after apportioning the concentration between the $\operatorname{Lp}(a)$ species far more comparisons were possible. Even then no consistent effect of either FDB or any of the mutations giving rise to FH was observed. Overall there was a slightly greater $(P$ $=0.067)$ concentration of $\operatorname{Lp}(\mathrm{a})$ associated with the alleles in FH subjects, but no evidence that a deficiency in the removal of apoB-containing particles through LDL receptors had any major effect upon $\mathrm{Lp}$ (a) catabolism. This agrees with our in vivo turnover experiments, which showed that the catabolic rate for $\mathrm{Lp}(\mathrm{a})$ was the same in FH subjects as in normal subjects (13).

There were 10 individuals in whom the concentration of an $\mathrm{Lp}$ (a) species was outside the typical range. In the majority of these it was either probable or possible that both alleles were affected, presumably as a result of some exceptional post-translational influence. However, in at least four cases the other allele was not similarly affected. In each of these the $\operatorname{Lp}(\mathrm{a})$ concentration was reduced from one generation to the next. The apo (a) gene appears to have undergone extensive recombination (15) and is still subject to mutations that can alter the allele size (10). Thus it is not unlikely that mutations could also be occurring that affect the rate of $\operatorname{Lp}(\mathrm{a})$ synthesis. Indeed, the changes observed here are reminiscent of the "anticipation" phenomenon, which has recently been attributed in fragile $\mathrm{X}$ syndrome and myotonic dystrophy to the presence of unstable DNA sequences associated with the genes (16).

The concentration of $L p(a)$ species containing the samesized apo (a) isoforms produced from different alleles varied as much as 200 -fold. This is far greater than the variation for the products of identical alleles and indicates that there must be a variety of different controlling influences at the apo(a) locus. Recent haplotype analysis using four polymorphic sites has revealed that there are usually multiple alleles of each size (15), and the results presented here suggest that many of these could contain sequence differences that affect transcription or later
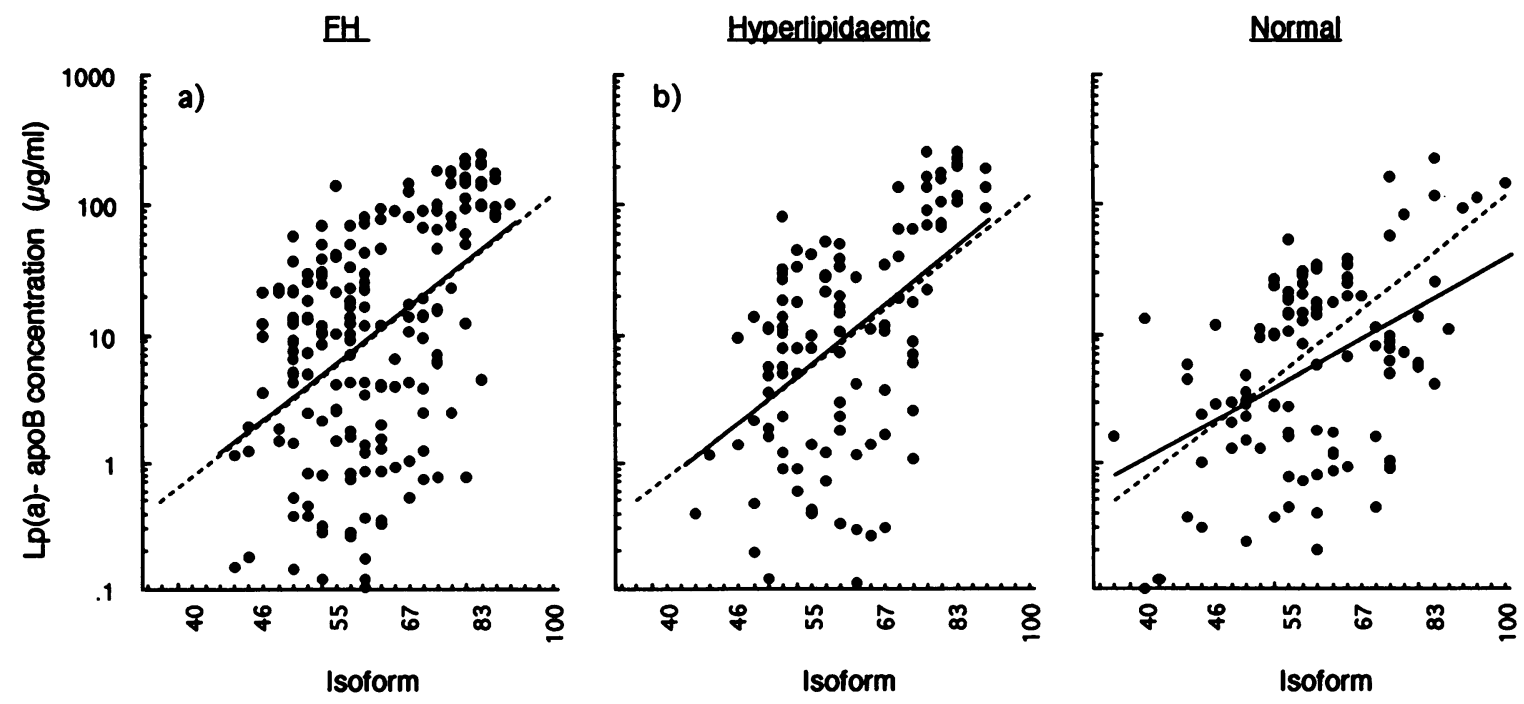

Figure 12. $\mathrm{Lp}(\mathrm{a})$-apoB concentrations associated with the apo(a) isoforms in FH (a), hyperlipidemic (b) and normal $(c)$ subjects. Apportioned Lp(a)-apoB values were obtained for $98 \mathrm{FH}$ subjects and 56 hyperlipidaemic (non-FH) subjects attending Lipid Clinics in London and for 51 normal subjects (see Methods). In each case the solid line represents the exponential line of best fit for the points shown, and the broken line the exponential line of best fit from the mean family values given in Fig. $11 b$. 


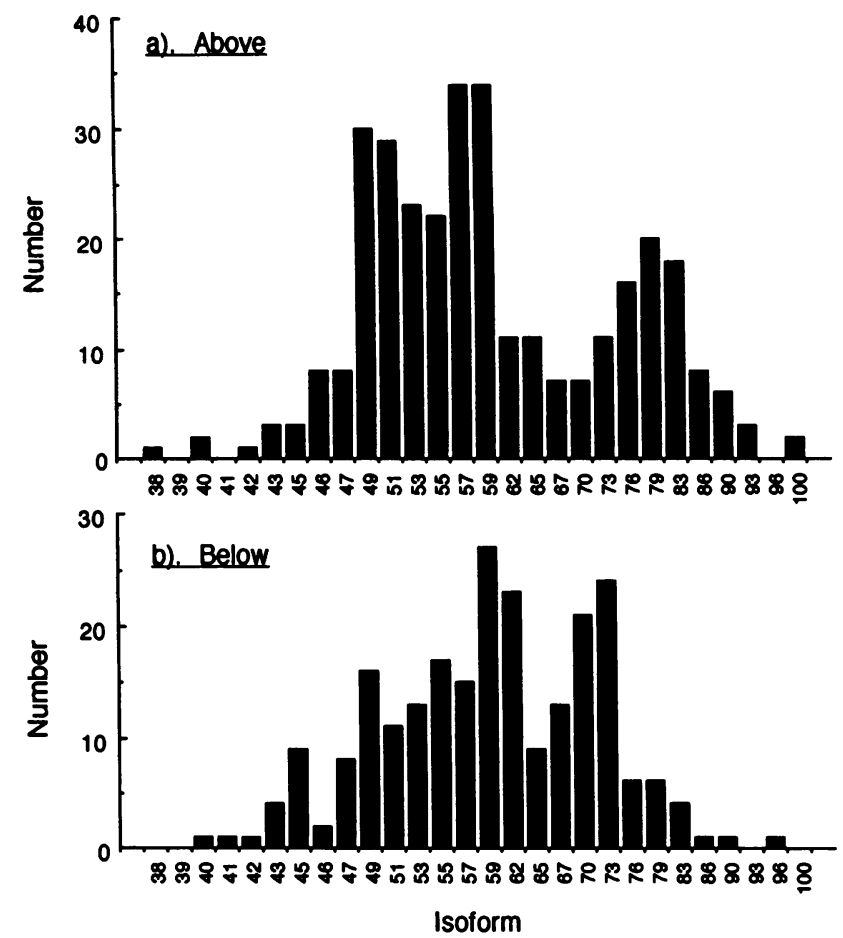

processing. If so, this raises the possibility that there may be distinct subpopulations of apo(a) alleles. The clustering of points on the diagrams relating $\mathrm{Lp}(\mathrm{a})$ concentration to apo(a) isoform supports such a possibility. In particular the frequency distribution of isoforms associated with high concentrations of $\mathrm{Lp}$ (a) suggests the presence of at least two groups, each containing a range of sizes with similar regulatory elements. There was a lower proportion of the highly expressed, small isoform group in the limited number of normal subjects studied, indicating that there could have been a fortuitous, if not unexpected, selection in the families and lipid clinic populations that allowed the presence of the subgroups to be revealed. On the other hand, a recent larger study of over 800 normal white subjects showed a bimodal distribution of apo (a) isoforms (9). Interestingly the frequency of the small isoforms was much lower in a population of black subjects (9). Thus the presence of these putative subgroups may vary between different ethnic populations, providing a possible explanation for the marked differences observed in the distribution of $\operatorname{Lp}(a)$ concentrations (17).

The apportioned values for $\operatorname{Lp}(\mathrm{a})$ concentration followed the general inverse trend with isoform size that has been deduced from phenotyping studies (7). As was observed previously for single isoform subjects (18) and also for the abundance of apo(a)-mRNA in human liver (19), the relationship between concentration and size was not linear. It is possible that the trend reflected the cumulative effect of a series of subpopulations. However, the smooth rise, even within the predicted subpopulations, suggests that it is more likely to result from an effect of size upon mRNA and protein stability, which is superimposed upon the other factors that give rise to the variation in concentrations observed for each sized isoform.

The ability to identify potential subpopulations and atypically expressed alleles provides a basis on which to examine more closely the factors that determine plasma $\operatorname{Lp}(\mathrm{a})$ concen-
Figure 13. Total numbers of each apo(a) isoform. Values shown are the total number of isoforms with associated $\mathrm{Lp}(\mathrm{a})$-apoB concentrations above $(a)$ or below $(b)$ the exponential line of best fit that was obtained in the family studies (Fig. $11 b$ ). They include the separate isoforms identified in the families and in the Lipid Clinic and normal populations ( see Methods).

trations. This will be facilitated at the gene level by the recent identification of the apo(a)-promoter region and of polymorphisms along the gene $(15,20,21)$. It will also be important to investigate the environmental and genetic causes of the variation in $\mathrm{Lp}(\mathrm{a})$ concentration associated with the same apo(a) allele. Although this is not statistically the major determinant of the final concentration (10), even a small difference in an already high value could have significant physiological effects. Elucidation of the factors that can influence $\mathrm{Lp}(\mathrm{a})$ concentrations, within this limited range, could have considerable clinical implications.

\section{Acknowledgments}

We thank Mrs. Sue McCarthy and Dr. Mary Seed for obtaining the blood samples used in this study, and Dr. Seed and Dr. Gilbert Thompson for access to their Lipid Clinic patients. Dr. Helen Hobbs (Dallas, TX) kindly provided the MP-1 probe used for genotyping.

This work was supported in part by a grant from the British Heart Foundation (Grant 91/57).

\section{References}

1. Scanu, A. M., and G. M. Fless. 1990. Lipoprotein(a): heterogeneity and biological relevance. J. Clin. Invest. 85:1709-1715.

2. Eaton, D. L., G. M. Fless, W. J. Kohr, J. W. McLean, Q-T. Xu, C. G. Miller, R. M. Lawn, and A. M. Scanu. 1987. Partial amino acid sequence of apolipoprotein(a) shows that it is homologous to plasminogen. Proc. Natl. Acad. Sci. USA. 84:3224-3228.

3. McLean, J. W., J. E. Tomlinson, W-J. Kuang, D. L. Eaton, E. Y. Chen, G. M. Fless, A. M. Scanu, and R. M. Lawn. 1987. cDNA sequence of human apolipoprotein (a) is homologous to plasminogen. Nature (Lond.). 300:132-137.

4. Lackner, C., E. Boerwinkle, C. C. Leffert, T. Rahmig, and H. H. Hobbs. 1991. Molecular basis of apolipoprotein (a) isoform size heterogeneity as revealed by pulsed-field gel electrophoresis. J. Clin. Invest. 87:2153-2161.

5. Lackner, C., and H. H. Hobbs. 1992. Molecular cloning and characterization of the Kringle 4-encoding region of the apolipoprotein gene. Circulation. 86 (Suppl.):I-337. (Abstr.)

6. Kraft, H. G., S. Köchl, H. J. Manzel, C. Sandholzer, and G. Utermann. 
1992. The apolipoprotein(a) gene: a transcribed hypervariable locus controlling plasma lipoprotein (a) concentration. Circulation. 86 (Suppl.):I-337. (Abstr.)

7. Utermann, G., H. J. Menzel, H. G. Kraft, H. C. Duba, H. G. Kemmler, and C. Seitz. 1987. Lp(a) glycoprotein phenotypes. J. Clin. Invest. 80:458-465.

8. Kamboh, M. I., R. E. Ferrell, and B. A. Kottke. 1991. Expressed hypervariable polymorphism of apolipoprotein(a). Am. J. Hum. Genet. 49:1063-1074.

9. Marcovina, S. M., Z. H. Zhang, V. P. Gaur, and J. J. Albers. 1993. Identifcation of 34 apolipoprotein(a) isoforms: differential expression of apolipoprotein(a) alleles between American blacks and whites. Biochem. Biophys. Res. Commun. 191:1192-1196.

10. Boerwinkle, E., C. C. Leffert, J. Lin, C. Lackner, G. Chiesa, and H. H. Hobbs. 1992. Apolipoprotein (a) gene accounts for greater than $90 \%$ of the variation in plasma lipoprotein (a) concentrations. J. Clin. Invest. 90:52-60.

11. Perombelon, Y. F. N., J. J. Gallagher, N. B. Myant, A. K. Soutar, and B. L. Knight. 1992. Lipoprotein (a) in subjects with familial defective apolipoprotein $\mathrm{B}_{100}$. Atherosclerosis. 92:203-212.

12. Myant, N. B., J. J. Gallagher, B. L. Knight, S. N. McCarthy, J. Frostegård, J. Nilsson, A. Hamsten, P. Talmud, and S. E. Humphries. 1991. Clinical signs of familial hypercholesterolemia in patients with familial defective apolipoprotein B-100 and normal low density lipoprotein receptor function. Arterioscler. Thromb. 11:691-703.

13. Knight, B. L., Y. F. N. Perombelon, A. K. Soutar, D. P. Wade, and M Seed. 1991. Catabolism of lipoprotein (a) in familial hypercholesterolaemic subjects. Atherosclerosis. 87:227-237.

14. Soutar, A. K., S. N. McCarthy, M. Seed, and B. L. Knight. 1991. Relationship between apolipoprotein(a) phenotype, lipoprotein(a) concentration in plasma, and low density lipoprotein receptor function in a large kindred with familial hypercholesterolemia due to the pro $_{664} \rightarrow$ leu mutation in the LDL receptor gene. J. Clin. Invest. 88:483-492.

15. Cohen, J. C., G. Chiesa, and H. H. Hobbs. 1993. Sequence polymorphisms in the apolipoprotein (a) gene. J. Clin. Invest. 91:1630-1636.

16. Sutherland, G. R., and R. I. Richards. 1992. Anticipation legitimized: unstable DNA to the rescue. Hum. Genet. 51:7-9.

17. Utermann, G. 1989. The mysteries of lipoprotein(a). Science (Wash DC). 246:904-910.

18. Gavish, D., N. Azrolan, and J. L. Breslow. 1989. Plasma Lp(a) concentration is inversely correlated with the ratio of kringle IV/kringle V encoding domains in the apo(a) gene. J. Clin. Invest. 84:2021-2027.

19. Wade, D. P., B. L. Knight, K. Harders-Spengel, and A. K. Soutar. 1991. Detection and quantitation of apolipoprotein(a) mRNA in human liver and its relationship with plasma lipoprotein(a) concentration. Atherosclerosis. 91:6372.

20. Wade, D. P., J. G. Clarke, G. E. Lindahl, A. C. Liu, B. R. Zysow, K. Meer, K. Schwartz, and R. M. Lawn. 1993. 5' control regions of the apolipoprotein(a) gene and members of the related plasminogen gene family. Proc. Natl. Acad. Sci. USA. 90:1369-1373.

21. Malgaretti, N., F. Acquati, P. Magnachi, L. Bruno, M. Pontoglio, M. Rocchi, S. Saccone, G. della Valle, M. D’Urso, D. LePaslier, et al. 1992. Characterization by yeast artificial chromosome cloning of the linked apolipoprotein (a) and plasminogen genes and identification of the apolipoprotein(a) 5 ' flanking region. Proc. Natl. Acad. Sci. USA. 89:11584-11588. 